\title{
Hidden Climate Change Notes in the Restoration Song
}

Steven N. Handel

\section{Our Journey}

We work under the spell of a Siren song, our motivation and enthusiasm driven by the values of restoration ecology that can improve our world. But like Ulysses in the Greek myth, a Siren's song can lead us astray and cause our voyage to flounder to destruction. Ulysses succeeded because he plugged his crew's ears so that they could not hear the song. We have no such remedy that can save us from project destruction; we must learn all that we can about what is around us to increase the probability that we will reach our project journey's end.

Ulysses had rough seas on his voyage and we too have physical challenges making steady progress difficult. These must be overcome. Our biggest challenge may be climate change and how it is transforming the habitats around us as we try to build new ones. Climate change has added discordant notes to the song that drives our work but sometimes they are difficult to hear.

\section{Our Shifting Biomes}

As climate changes, all species are challenged to disperse into favorable environments. This is not simply a slow march north or up a mountainside as climate warms, but an irregular progression where landform, hydrology, and geography modify the movement north or up. We have good evidence that different tree species have migrated in idiosyncratic ways as the earth warmed since the last glaciation. Margaret Davis' classic work has shown that our major habitat types get modified as tree species disperse at individual rates. Today's forest communities, for example, are not defined tree groupings that moved north as the glacier melted. Community membership varies, influenced by local conditions, dispersal, and demographic criteria. We do not know how existing communities will migrate in the coming warmer centuries for these reasons. Human land-use modifications add high new hurdles over which plant species must cross.

Ecological Restoration Vol. 38, No. 2, 2020

ISSN 1522-4740 E-ISSN 1543-4079

@2020 by the Board of Regents of the University of Wisconsin System.
Davis' work suggests that the degree of climate change on the ground can be ten times faster than the ability of tree dispersal to reach that location. That is, tree dispersal is relatively slow compared to the trajectory of climate warming that we are experiencing. Consequently, range and density of many species will shrink. The dance of the trees across the land in response to the climate change song is not synchronous, like the high kicks of the Rockettes. The movement is erratic, seemingly chaotic, as each species responds differently to the tempo.

Other studies have shown that the dispersal ability of vertebrates and invertebrates are also inadequate to keep pace with the new temperature regime molded by climate change. Their ranges will shrink. The hypothesis that natural dispersal is inadequate to move our habitats to favorable locations must be entertained. Our siren's song may encourage us to restore the habitats recently present on our local landscapes, but we will struggle without the agency of natural dispersal. Long-term dispersal is often invisible during our work; it is a hidden chorus of the restoration song we love.

\section{The Need for Partners}

Sustainable habitats are, of course, not simply plant species but also the suite of mutualists upon which they depend. Much work has been done on pollinators and on food web dynamics showing the many kinds of species necessary to allow even the dominant plants in our habitats to reproduce. Pollinators, for example, have their own life history niche axes which are being altered by climate change. Generation time, recruitment requirements, and interspecific relationships among guild members all shift as the climate changes. The community envelope within which plants thrive is being torn. The subtleties of these interactions are maddening. With decreasing snowpack some insects may have larger populations as the ground becomes warmer and the season for flight and reproduction is longer. Other insects may crash as their overwintering stages are more frequently exposed to winter temperatures and die. Parasites and parasitoids of mutualists will have their own life histories changed as the climate warms. The result is a rearrangement of the mutualist community upon which 
plants depend. These interactions are difficult to see and to investigate experimentally.

Even elegant experiments are done at rather small scale and may not reflect the many spatial interactions which can occur in nature. For example, the influential work on sequential mutualisms of Waser and Real suggested that pollinators need a series of flowering plant species blooming across the season to persist. After the flowering period of one plant ends, another must be present to provide forage to those insects which can feed over the growing season. The insect populations can hold on or sometimes build up until the fall when the process stops. The next spring, the still present and perhaps larger insect population can start servicing the first flowers of the new season. We know there are pollinator networks at work in our habitats that involve many insects and many plant species. The temporal axis that binds this network together is a level of complexity most restoration designers would have difficulty managing.

\section{Defending Against Enemies}

Other hidden notes in the melody around us are plant responses set in motion by their enemies in a changing physical world. There are complex chemical interactions involving metabolites and nutrients. Plants may grow faster with heat and more carbon dioxide in the air, but the concentration of nitrogen may not match the increased growth rate. Some herbivores must eat more plant tissue to ingest enough nitrogen to meet their own metabolic needs. More plant tissue is made but the rate of herbivory is even higher. Plants have their own chemical defenses against their enemies and many of these require nitrogen for synthesis. There may be a switch of chemical defenses in plants as carbon and nitrogen stocks are modified. This will affect the food web as different insects have evolved their own defenses against the plants' varied protections.

The changing nutrient status accompanying climate change will cause stress in many plant species. This could increase disease susceptibility. In some areas there will be more rain yielding a higher sporulation rate of disease organisms. Changing hydrology may also increase the number of moist surfaces upon which fungal and other pathogen spores can adhere. The upshot of this is that the new community dynamics during climate change is much more than simply change in the range of the canopy tree species. The interspecific interactions, so many invisible to us, will underlie the main changes we see. Like the deep bass notes in an orchestra performance and the steady drumbeat of the percussion section, these elements are present although we concentrate on the more obvious melodic themes. The song of restoration that drives us will be changing in inconspicuous but significant ways.

\section{Finishing the Song}

As in the Greek myth, we are driven by temptation and longing for a return to a home, the dream of a better future. Can we resist the simple Siren's song we hear to grapple with the multiple low notes also must be heard to successfully reach the end of our restoration journeys? Unlike Ulysses, we do not have the option to plug our partners' ears and to bind ourselves to a mast to keep our voyages true. We must be aware of these more subtle and hidden components around us as we hope for successful landings of our restoration projects.

\section{Recommended Readings}

Bakkenes M., J.R.M. Alkemade, F. Ihle, R. Leemans and J.B. Latour. 2002. Assessing effects of forecasted climate change on the diversity and distribution of European higher plants for 2050 . Global Change Biology 8:390-407.

Davis, M.B. 1989. Lags in vegetation response to greenhouse warming. Climatic Change 15:5-82.

Dukes, J.S., J. Pontius, D. Orwig, J.R. Garnas, V.L. Rodgers, N. Brazee, et al. 2009. Responses of insect pests, pathogens, and invasive plant species to climate change in the forests of northeastern North America: What can we predict? Canadian Journal of Forestry Research 39:231-248.

Forrest, J.R. 2015. Plant-pollinator interactions and phenological change: What can we learn about climate impacts from experiments and observations? Oikos 124:4-13.

Iverson, L.R. and A.M. Prasad. 2001. Potential changes in tree species richness and forest community types following climate change. Ecosystems 4:186-199.

Morton, E.M. and N.E. Rafferty. 2017. Plant-pollinator interactions under climate change: The use of spatial and temporal transplants. Applications in Plant Sciences 5:1600133.

Van der Putten, W.H., M. Macel and M.E. Visser. 2010. Predicting species distribution and abundance responses to climate change: Why it is essential to include biotic interactions across trophic levels. Philosophical Transactions of the Royal Society B: Biological Sciences 365:2025-2034.

Warren, R., J. Price, E. Graham, N. Forstenhaeusler and J. VanDerWal. 2018. The projected effect on insects, vertebrates, and plants of limiting global warming to $1.5 \mathrm{C}$ rather than $2 \mathrm{C}$. Science 360:791-795.

Waser, N.M. and L.A. Real. 1979. Effective mutualism between sequentially flowering plant species. Nature 281:670-672. 